\title{
STUDIES ON THE ANTIBACTERIAL AND ANTICORROSIVE PROPERTIES OF SYNTHESIZED HYBRID POLYURETHANE COMPOSITES FROM CASTOR SEED OIL
}

\author{
T.O. Siyanbola ${ }^{1^{*}}$, A. F. Akinsola ${ }^{2}$, O. R. Obanla ${ }^{3}$, A. A. Adebisi ${ }^{1}$, A. A.

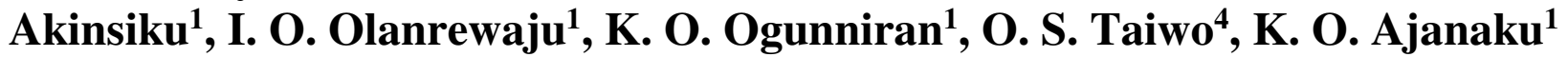 \\ and O. A. Bamgboye ${ }^{1}$ \\ ${ }^{1}$ Department of Chemistry, College of Science and Technology, College, Covenant University, \\ P.M.B. 1023, Ota, Ogun State, Nigeria \\ ${ }^{2}$ Department of Chemistry, Faculty of Science, Ekiti State University, \\ P.M.B. 5363, Ado-Ekiti, Nigeria \\ ${ }^{3}$ Department of Chemical Engineering, College of Engineering, Covenant University, \\ P.M.B. 1023, Ota, Ogun State, Nigeria \\ ${ }^{4}$ Department of Biological Sciences, College of Science and Technology, Covenant University, \\ P.M.B. 1023, Ota, Ogun State, Nigeria \\ *E-mail: tolu.siyanbola@ covenantuniversity.edu.ng
}

\begin{abstract}
Castor seed oil (Ricinus communis) is a prominent feed stock towards the generation of renewable materials for industrial production. The reach presence of ricinoleic fatty acid at $87.5 \%$ provides pendant hydroxyl functional groups, which is an essential site for chemical formulations. This paper presents the synthesis, characterization, and evaluations on antibacterial and anticorrosive activities of synthesized hybrid composites from Ricinus communis seed oil. $N, N^{\prime}$-bis(2-hydroxy ethyl)-12-hydroxy Ricinus communis oil fatty amide (HERCA) was synthesized via aminolysis polyol formation route. Upon reacting HERCA with succinic acid at a high temperature of about $145^{\circ} \mathrm{C}$, a polyesteramide (RCPEA) was formed. This ester product undergoes urethanation and subsequently interfaced with modified hybrid material. The synthesized composites were characterized using spectroscopic methods such as FTIR, ${ }^{1} \mathrm{H}-\mathrm{NMR}$, and ${ }^{13} \mathrm{C}-\mathrm{NMR}$. Selected physicochemical parameters were also carried out on the products. Coating performance on cured resins was examined.
\end{abstract}

Keywords: Ricinus communis, ricinoleic, polyesteramide, urethanation, coating

@ RASĀYAN. All rights reserved

\section{INTRODUCTION}

The development of industrial products like coatings, elastomers, fibers, forms, lubricants, cosmetics, biodiesel etc. has been manufactured through petroleum based feed stocks over the years. These feed stocks are non-biodegradable hence, capable of triggering life-threating environmental issues like water and air pollutions, increase in world temperature and culminating in ocean levels rise. These global issues can be subdued by the use of resource materials that are eco-friendly and renewable such as seed oils, polysaccharides (basically cellulose and starch), proteins, natural rubber, wood, and others as sustainable substitute for petroleum based feed stocks, which have finite reserves. ${ }^{1-3}$ Amidst these renewable materials aforementioned, seed oils are most widely used as base materials for polymer and chemical industries due to their low toxicity, low price, ready availability and biodegradability. ${ }^{2,4}$

Seed oils comprising of different fatty acids compositions are obtained from plants such as soybean, yellow oleanda, Pogamia glabra, sunflower, linseed, tung oil, safflower, castor etc. The fatty acids profile of castor oil differs extensively from that of other plant seed oils. The presence of its $87.5 \%$ ricinoleic acid creates easy modifications through the C-12 hydroxy functional group. However, further modifications (i.e. metathesis, hydrolysis, epoxidation, halogenation, hydroformylation, and aminolysis) 
on the seed oil can also be carried out in other to increase the presence of reactive sites for the development of polymeric organic coatings like alkyds, polyetheramides, epoxies, polyurethanes, polyesteramide and other resins. ${ }^{5-6}$

In this study, a non-drying shrub-like plant seed oil (Ricinus communis) having $40 \%$ to $60 \%$ seed oil content was modified through aminolysis in order to increase its hydroxy functionality; this prepared polyol was used for the synthesis of pristine and hybrid polyurethane composites. The need to formulate coatings with hybrid materials cannot be overemphasized. These materials improve the physicomechanical, antimicrobial and anticorrosive properties of synthesized coating composites. Amine functionalized $\mathrm{ZnO}$ nanomaterials was prepared using 0.1 weight percent of 3-amino propyl tri-methoxy silane (APTMS). ${ }^{1,6}$ The surface modified hybrid material (ZnO-APTMS) leads to the formation of urea linkages with dislodge-NCO unit groups in the polyurethane (PU) matrix. Synthesized polymer composites were characterized using Fourier transform infrared spectroscopy (FT-IR), ${ }^{1} \mathrm{H}$ NMR, ${ }^{13} \mathrm{C}$ NMR, scanning electron microscopy (SEM). Antibacterial, anticorrosive property and salt spray evaluations were also carried out on the synthesized composites.

\section{Materials and Methods}

\section{EXPERIMENTAL}

Ricinus communis seeds were collected from Ado-Ekiti, South-Western Nigeria. Air-dried seedlings were mildly pulverized using blender and Soxhlet apparatus was used in the extraction of oil from the seeds with $n$-hexane as solvent. Toluene, sodium methoxide, diethanolamine, $n$-hexane, diethyl ether, isophthalic acid, xylene, 4-methyl pentane-2-one, anhydrous sodium sulfate was obtained from S.D. Fine Chemicals (Mumbai, India). Isophorone diisocyanate (IPDI) and $\mathrm{ZnO}$ nano powder (particle size 50-70 $\mathrm{nm}$ ) were procured from Alfa Aesar chemical UK and Aldrich (Milwaukee, WI) respectively. 3-amino propyl trimethoxy silane (APTMS) from Aldrich was used.

The confirmation of chemical structure of $N, N^{\prime}$-bis(2-hydroxy ethyl)-12-hydroxy Ricinus communis oil fatty amide (HERCA), Ricinus communis polyesteramide (RCPEA), APTMS modified ZnO and hybridNCO terminated polyurethane composites (PURFA-ZnO-APTMS) were carried out on FTIR, ${ }^{1} \mathrm{H}-\mathrm{NMR}$, and ${ }^{13} \mathrm{C}-\mathrm{NMR}$. The FT-IR spectra of all samples were taken on Bruker Table-Top Platinum ATR (Laser Class I, Model Alpha). ${ }^{1} \mathrm{H}-\mathrm{NMR}$ and ${ }^{13} \mathrm{C}-\mathrm{NMR}$ were respectively recorded on a Varian VXR-Unity 200 $\mathrm{MHz}$ spectrometer and a Bruker UXNMR $400 \mathrm{MHz}$ spectrometer by using $\mathrm{CDCl}_{3}$ or $\mathrm{DMSO}^{-\mathrm{d}_{6}}$ as dissolving solvent and tetramethyl silane (TMS) as an internal standard. The acid and hydroxyl values of the resin samples were determined by using the ASTM D1639-89 and ASTM D4274-94 procedures. The morphological studies were carried out on a SEM Hitachi-S520 (Oxford link ISIS-SEM model), Japan. Elcometer was used to obtain the thickness of the coatings on metal steel panels. A refractometer RFM 800 instrument was used to analyze the refractive indices of all the resin samples ${ }^{1}$. In vitro antimicrobial activity of the polymers was tested against Gram-positive organisms' viz. Bacillus subtilis (MTCC 441), Staphylococcus aureus (MTCC96) and Gram-negative organisms' viz. Escherichia coli (MTCC 443), and Pseudomonas aeruginosa by the agar diffusion method. ${ }^{7}$ The ready-made nutrient agar was suspended in double distilled water $(1,000 \mathrm{ml})$ and heated to boiling for $25 \mathrm{~min}$ until it dissolved completely; the medium and Petri dishes were autoclaved at a pressure of $15 \mathrm{lb} / \mathrm{in} 2$. The medium was transferred into sterile Petri dishes under aseptic conditions in a laminar air flow chamber. When the medium in the plates had solidified, $0.5 \mathrm{ml}$ (approx. $106 \mathrm{CFU} / \mathrm{ml}$ ) of the culture of test organism was inoculated and evenly spread over the agar surface with a sterile L-shaped rod. Embedded polymer samples with $2 \mathrm{~cm} \times 2 \mathrm{~cm}$ (approx.) samples were cleaned with double distilled water and placed on the medium and incubated at 37 ${ }^{\circ} \mathrm{C}$ for $24 \mathrm{~h}$. The antibacterial activity was carried out based on the formation of an inhibition zone and loss of growth of organisms beneath and surrounding the films placed on the agar medium. Three replicates were used for each treatment. MTCC is the Microbial Type Culture Collection in IMTECH (CSIR LAB) Chandigarh, India. Different grades of Silicon carbide papers were used for the preparation of mild steel strips; which were washed with water, ethanol, and acetone. The de-greased metal strips were dried under a vacuum for $3 \mathrm{~h}$. The pristine and hybrid coatings were prepared by brush application. ${ }^{1}$ 


\section{Synthesis of $N, N^{\prime}$-bis(2-hydroxy ethyl)-12-hydroxy Ricinus communis oil fatty amide (HERCA)}

HERCA was prepared by reacting 6:1 molar ratio of diethanolamine and Ricinus communis seed oil in a four necked round bottom Pyrex flask fitted with mechanical stirrer, condenser, and thermometer in the presence of $2 \%$ sodium methoxide as catalyst. Mechanical stirring of the mixture at $115{ }^{\circ} \mathrm{C}$ in the four necked flasks continued until the product (HERCA) was formed. Thin layer chromatography (TLC) was used to monitor the progress of the reaction. The reaction product (Scheme-1) was allowed to cool and dissolved in diethyl ether in a separation funnel. The ethereal layer was washed with $5 \%$ aqueous hydrochloric acid. The ether layer was separated and washed with water and later dried over anhydrous sodium sulfate. The concentration of HERCA in the ethereal layer was carried out using rotary evaporator. ${ }^{5,9}$

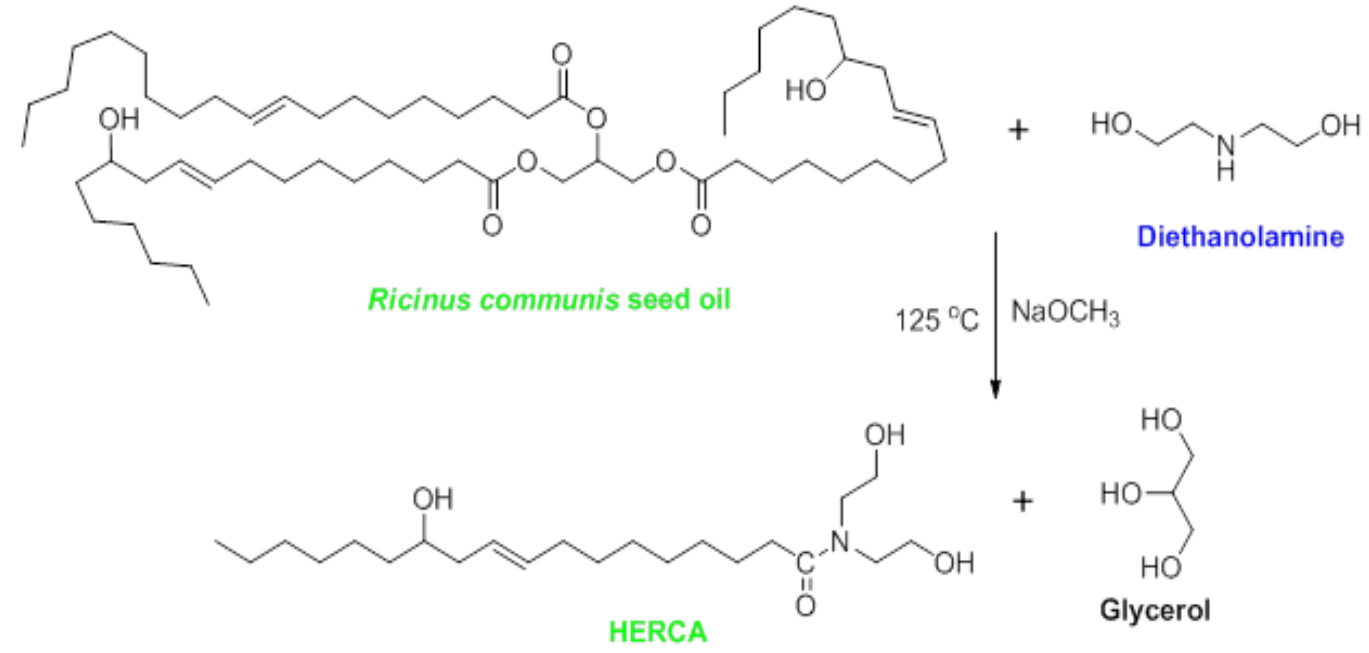

Scheme-1: Synthesis of $N, N^{\prime}$-bis(2-hydroxy ethyl)-12-hydroxy Ricinus communis oil fatty amide (HERCA)

\section{Synthesis of Ricinus communis polyesteramide (RCPEA)}

RCPEA was synthesized by reacting HERCA $(0.0582 \mathrm{~mol})$ with succinic acid $(0.0291 \mathrm{~mol})$ and $26 \mathrm{ml}$ xylene in a four neck round bottom flask connected to a Dean Stark, thermometer, mechanical stirrer, and a nitrogen inlet tube. The reaction mixture was refluxed at $145-150{ }^{\circ} \mathrm{C}$ until the theoretical amount of water was collected and the reaction was monitored by the determination of acid value at regular intervals (Scheme-2). ${ }^{5,9}$ At the end of the reaction the product (RCPEA) was taken out of the four neck round bottom flask and xylene (solvent) was withdrew from the compound using rotary evaporator under reduced pressure. ${ }^{5}$

\section{Modification of $\mathrm{ZnO}$ peripheral with APTMS}

In a $500 \mathrm{ml}$ round bottom flask, $50 \mathrm{~g}$ toluene and $10 \mathrm{~g} \mathrm{ZnO}$ powder were added and stirred for $10 \mathrm{~min}$ using a magnetic stirrer $30 \mathrm{~min}$ of the ultrasonic bath was carried out so as to make a uniform suspension. To this suspension, $1 \mathrm{~g}$ of APTMS was added and the resulting mixture was stirred at room temperature for $1 \mathrm{~h}$. A slightly yellow-transparent coloration was obtained. The reaction mixture was refluxed for $24 \mathrm{~h}$ (Scheme-3). The rotary evaporator was used to remove the solvent from the APTMS modified $\mathrm{ZnO}$ (APTMS-ZnO). Unreacted APTMS was removed by washing the compound with ethanol. The powder was dried at $50{ }^{\circ} \mathrm{C}$ for $1 \mathrm{~h}$ in an oven. The modified powder was ground and further dried at $100{ }^{\circ} \mathrm{C}$ for 2 h. ${ }^{5,10}$

\section{Synthesis of hybrid-NCO terminated polyurethane composites (PURFA-ZnO-APTMS)}

In about $7 \mathrm{ml}$ of 4-methyl pentane-2-one in a three neck round bottom flask fitted with nitrogen gas inlet, thermometer, and dropping funnel, $5.02 \mathrm{~g}$ of RCPEA was dissolved. The calculated amount of $\mathrm{ZnO}-$ APTMS was added and kept in an ultrasonic bath for sonification. 
RASĀYAN J. Chem.

Vol. 10 | No. 3 |1003 - 1014 | July - September | 2017<smiles>CCCCCCC(O)CC=CCCCCCCCC(=O)N(CCO)CCO</smiles>

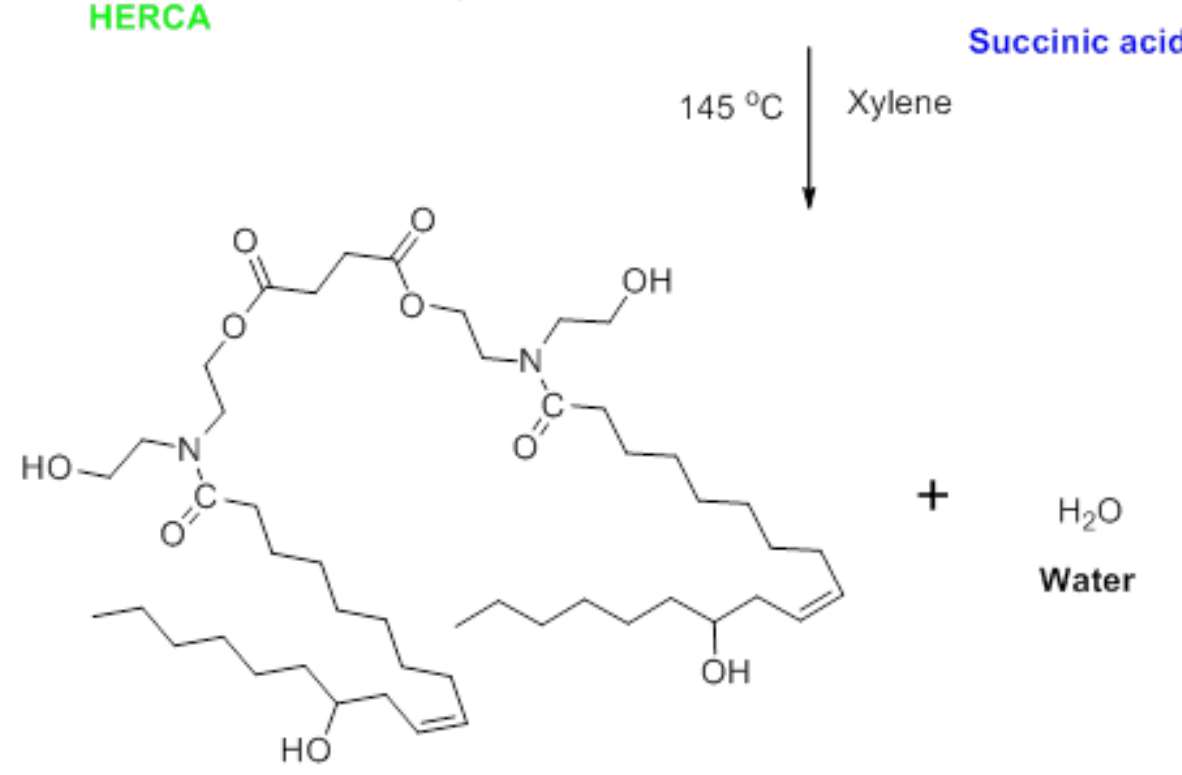

RCPEA

Scheme-2: Synthesis of Ricinus communis polyesteramide (RCPEA)

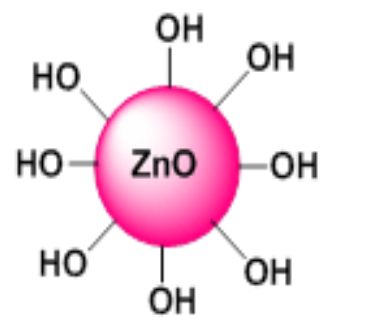

ZnO nanoparticles

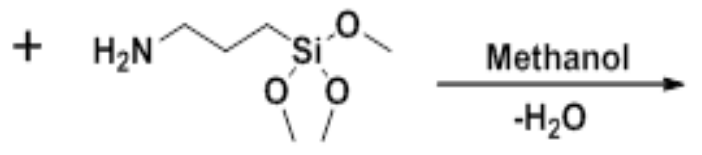

APTMS

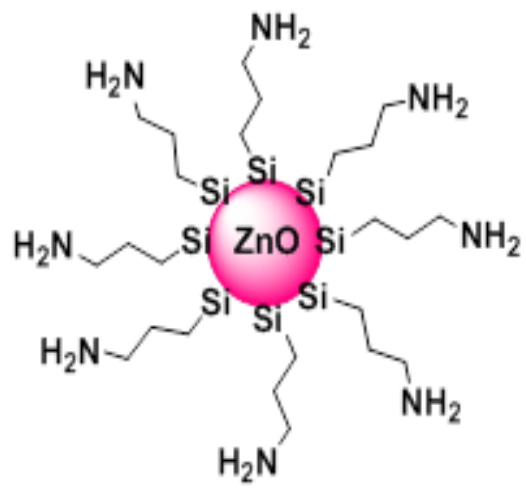

APTMS modified ZnO

Scheme-3: Modification of $\mathrm{ZnO}$ peripheral with APTMS

To the reaction mixture, $1.42 \mathrm{ml}$ of 5-Isocyanate-1-isocyantomethyl-1,3,3-trimethyl-cyclohexane [also known as isophorone diisocyanate (IPDI)] was dissolved in $2 \mathrm{ml}$ of 4-methyl pentane-2-one and added in a drop-wise manner into the reaction flask. The whole mixture was then heated at $75{ }^{\circ} \mathrm{C}$ for $3 \mathrm{~h}$ (Scheme 4). The progress of the reaction was monitored by TLC and hydroxyl value determination. Pristine PURFA coating films were also prepared. Finally, the pristine and hybrid composites films were obtained by casting the solution on a tin foil and mild steel panels and allowed to cure at ambient temperature. After curing, tin foil was removed by amalgamation with mercury to get free films. Cured films (with 6 $\mu \mathrm{m}$ and 90-115 $\mu \mathrm{m}$ thickness for foil and mild steel panels respectively) were coded as PURFA, PURFAZnO-APTMS (2 wt $\%$ ), PURFA-ZnO-APTMS (5 wt $\%$ ): where 2 and 5 corresponds to wt $\%$ of nanoparticles in the polymer matrix..$^{1,5,10}$ 
RASĀYAN J. Chem.

Vol. 10 | No. 3 |1003 - 1014 | July - September | 2017

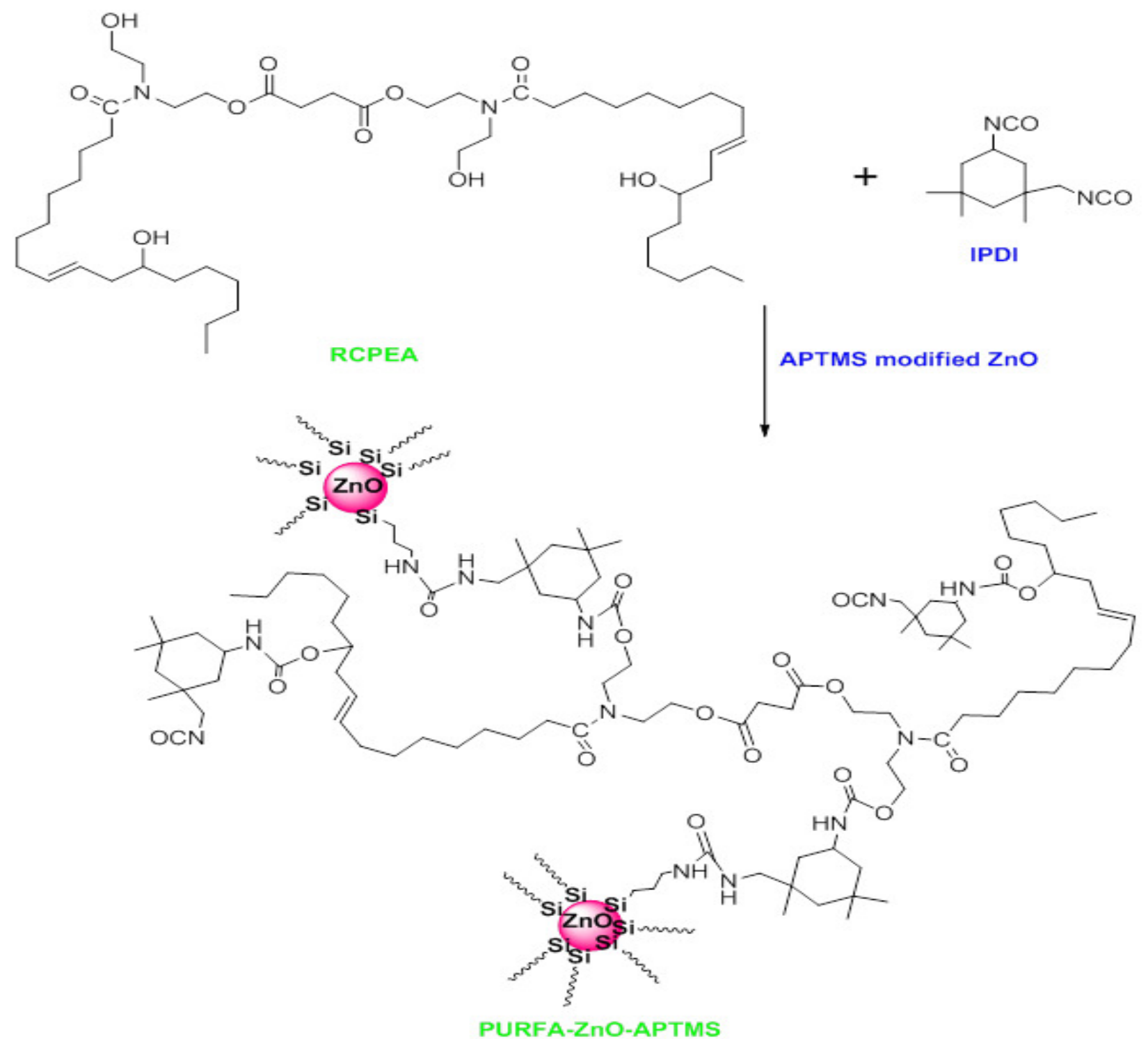

Scheme-4: Synthesis of hybrid-NCO terminated polyurethane composites (PURFA-ZnO-APTMS)

\section{FTIR and NMR spectra}

\section{RESULTS AND DISCUSSION}

Figure-1 shows the overlay FT-IR spectra of RCSO, HERCA, and RCPEA. The broad absorption stretching band at $3407.01 \mathrm{~cm}^{-1}$, confirms the presence of -OH group on position $\mathrm{C}-12$ of ricinoleic fatty acid (RCSO). Also, the characteristic stretching vibrations at $3342.65 \mathrm{~cm}^{-1}$ and $3377.66 \mathrm{~cm}^{-1}$ corresponds to the respective -OH functional group on HERCA, and RCPEA. Asymmetric and symmetric stretching vibrations of RCSO, HERCA, and RCPEA were respectively observed at $\left(2941 \mathrm{~cm}^{-1}\right.$ and $\left.2853 \mathrm{~cm}^{-1}\right)$, $\left(2924.07 \mathrm{~cm}^{-1}\right.$ and $\left.2853.43 \mathrm{~cm}^{-1}\right)$ and $\left(2924.21 \mathrm{~cm}^{-1}\right.$ and $\left.2853.63 \mathrm{~cm}^{-1}\right)$. However, the absence of ester carbonyl $(-\mathrm{C}=\mathrm{O})$ group on HERCA and its presence as sharp stretching vibration on RCPEA at 1736.14 $\mathrm{cm}^{-1}$ affirms the formation of RCPEA. The amide carbonyl $(-\mathrm{C}=\mathrm{O})$ functional group observed at 1619.50 $\mathrm{cm}^{-1}$ and $1626.61 \mathrm{~cm}^{-1}$ for HERCA and RCPEA respectively and the $\mathrm{C}-\mathrm{N}$ vibration at $1051.21 \mathrm{~cm}^{-1}$ for RCPEA also corroborates the formation of these compound(s).

The ${ }^{1} \mathrm{H}$ NMR spectrum of HERCA in Figure 2 also confirms the synthesis of the polyol. The signals occurring at $\delta=0.88-0.89 \mathrm{ppm}$ represent the terminal methyl $\left(-\mathrm{CH}_{3}\right)$ protons of the fatty acid chain. The 
internal methylene $\left(\mathrm{CH}_{2}\right)$ protons of the fatty acid chains are observed at $\delta=1.25-2.39 \mathrm{ppm}$ while the double bond ( $-\mathrm{CH}=\mathrm{CH}-$ ) protons resonate at $\delta=5.42 \mathrm{ppm}$. The methylene protons at position " $\mathrm{n}$ " and "o" resolves at $\delta=3.48 \mathrm{ppm}$ and $\delta=3.75 \mathrm{ppm}$ respectively. The bis-hydroxyl $(-\mathrm{OH})$ protons are sited at $\delta=$ $4.19 \mathrm{ppm}$, whereas the hydroxyl $(-\mathrm{OH})$ proton on the ricinoleic fatty acid chain resonates at $\delta=3.61 \mathrm{ppm}$. From the ${ }^{1} \mathrm{H}$ NMR spectrum of RCPEA (Fig.-3) the following assigned peaks confirm the formation of RCPEA polyesteramide in Scheme-2. Chemical shift of terminal methyl $\left(-\mathrm{CH}_{3}\right)$ group and its alpha methylene $\left(-\mathrm{H}_{3} \mathrm{C}-\mathrm{CH}_{2}-\right)$ protons of RCPEA resonates at $\delta=0.88 \mathrm{ppm}$ and $\delta=1.32 \mathrm{ppm}$. Protons attached to double bonds $(-\mathrm{CH}=\mathrm{CH}-)$ and its immediate alpha methylene group towards amide carbonyl on the straight chains are respectively represented at $\delta=5.42 \mathrm{ppm}$ and $\delta=2.18 \mathrm{ppm}$. The methylene group at position " $\mathrm{m}$ " is observed at $\delta=2.33 \mathrm{ppm}$. The polyester bond methylene $\left(-\mathrm{CH}_{2}-\mathrm{OOC}-\mathrm{CH}_{2}-\mathrm{CH}_{2}-\mathrm{COO}-\right.$ $\mathrm{CH}_{2-}$ ) linkage protons resonate at $\delta=4.23$ ppm confirming the formation of RCPEA.

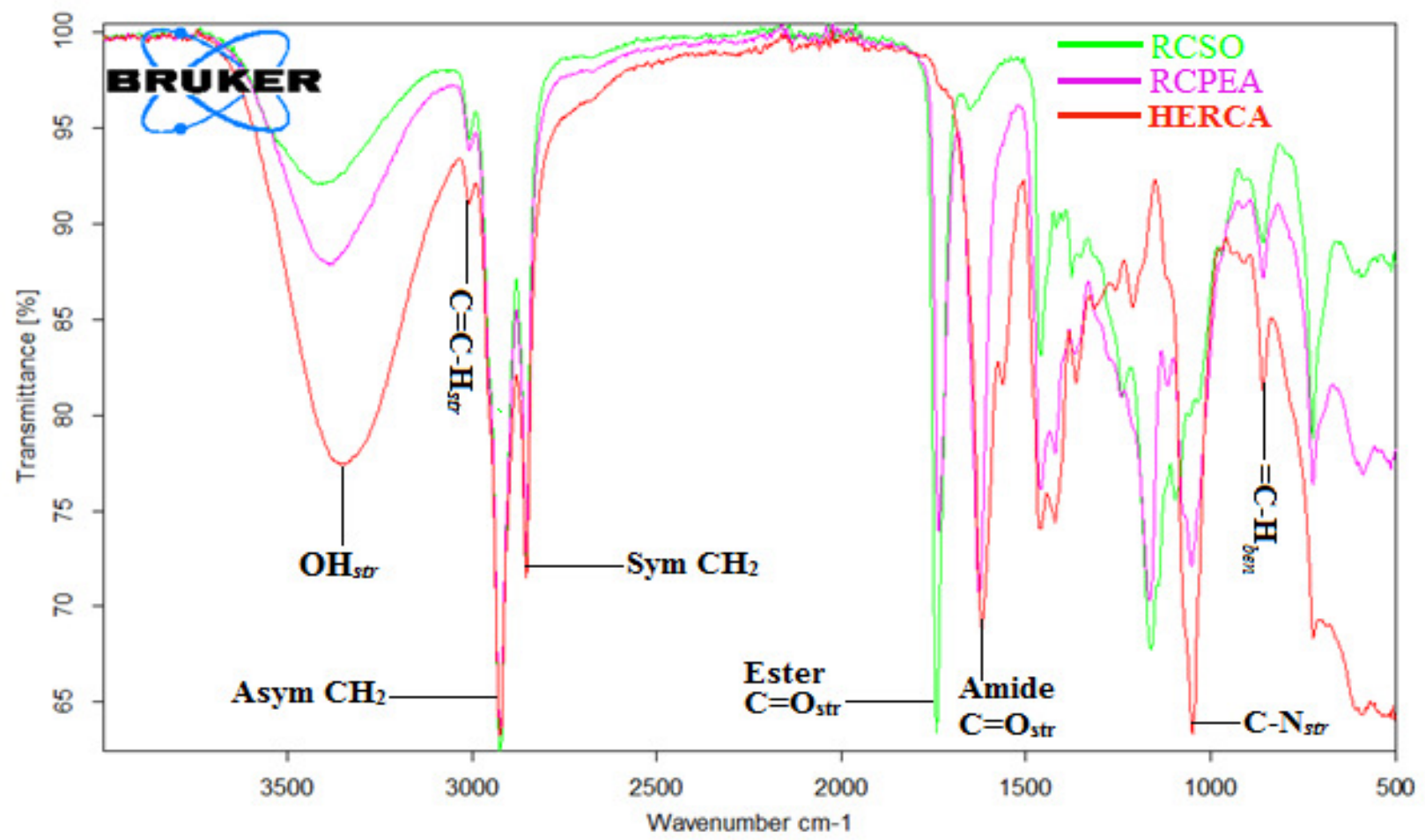

Fig.-1: Overlay FT-IR spectra of RCSO, HERCA, and RCPEA

The pristine FTIR spectrum of PURFA coating is illustrated in Figure 4. The broad stretching vibrational peak of $-\mathrm{NH}$ at $3359.40 \mathrm{~cm}^{-1}$ and the absence of $2100-2270 \mathrm{~cm}^{-1}$ FTIR $-\mathrm{NCO}$ region band is a clear indication of urethanation of RCPEA by IPDI. Stretching absorption bands of symmetric and asymmetric $-\mathrm{CH}_{2}$ of the fatty amide chains respectively appears at 2854.17 and $2924.11 \mathrm{~cm}^{-1}$. The stretching vibration of amide carbonyl $(-\mathrm{C}=\mathrm{O})$ is observed at $1698.18 \mathrm{~cm}^{-1}$ while that of the ester is seen at $1740.40 \mathrm{~cm}^{-1}$. $-\mathrm{CN}$ stretching peak appears at $1380.29 \mathrm{~cm}^{-1}$ but $1523.49 \mathrm{~cm}^{-1}$ corresponds to $-\mathrm{NH}$ deformation peak.

The PURFA ${ }^{1} \mathrm{H}$ NMR spectrum (Figure 5) shows confirmatory characteristic signals of urethane formation. Terminal protons of PURFA fatty acid chains $\left(\mathrm{CH}_{3^{-}}\right)$resonate at $\delta=0.81 \mathrm{ppm}$, the alpha methylene protons to the terminal protons $\left(\mathrm{CH}_{3}-\mathrm{CH}_{2}-\right)$ signal at $\delta=1.31 \mathrm{ppm}$. The internal methylene protons at "c" and "d" on the fatty acid chain are respectively observed at $\delta=1.29 \mathrm{ppm}$ and $\delta=1.25 \mathrm{ppm}$, while the characteristic signal at $\delta=5.34 \mathrm{ppm}$ represent the double bond protons of the fatty acid chain. The urethane $\mathrm{N}-\mathbf{H}$ chemical shift at $\delta=8.20 \mathrm{ppm}$ and the presence of methylene protons attached to oxygen connecting the urethane functional groups $\left(-\mathrm{CH}_{2}-\mathrm{O}-\mathrm{CO}-\mathrm{NH}-\right)$ at $\delta=4.20 \mathrm{ppm}$ gave a clear indication of urethane formation. The methylene protons on IPDI ring is observed at $\delta=0.93 \mathrm{ppm}$ and $\delta=$ 1.04 ppm respectively. 
RASĀYAN J. Chem.

Vol. 10 | No. 3 |1003 - 1014 | July - September | 2017

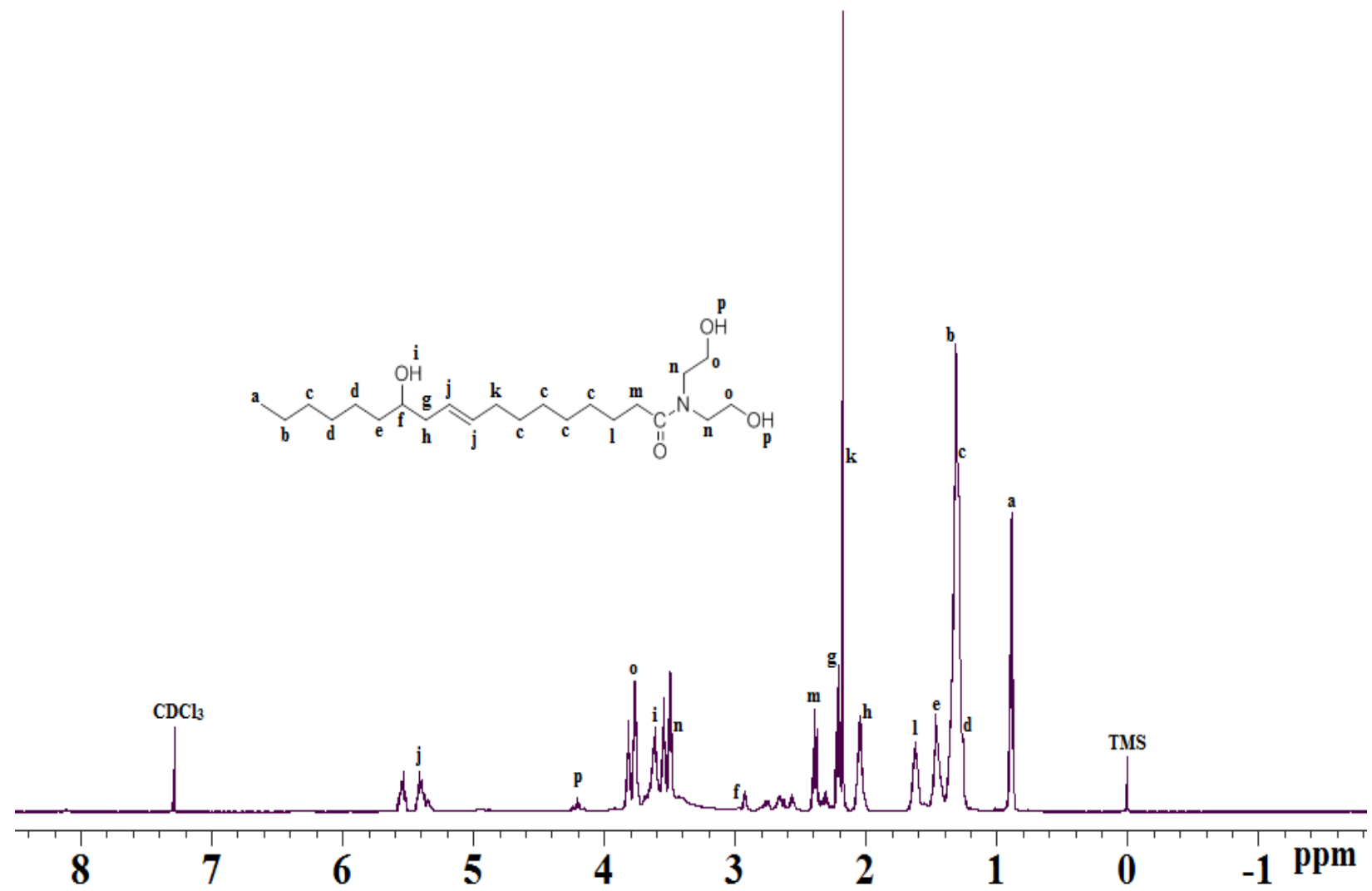

Fig.-2: ${ }^{1} \mathrm{H}-\mathrm{NMR}$ Spectrum of HERCA

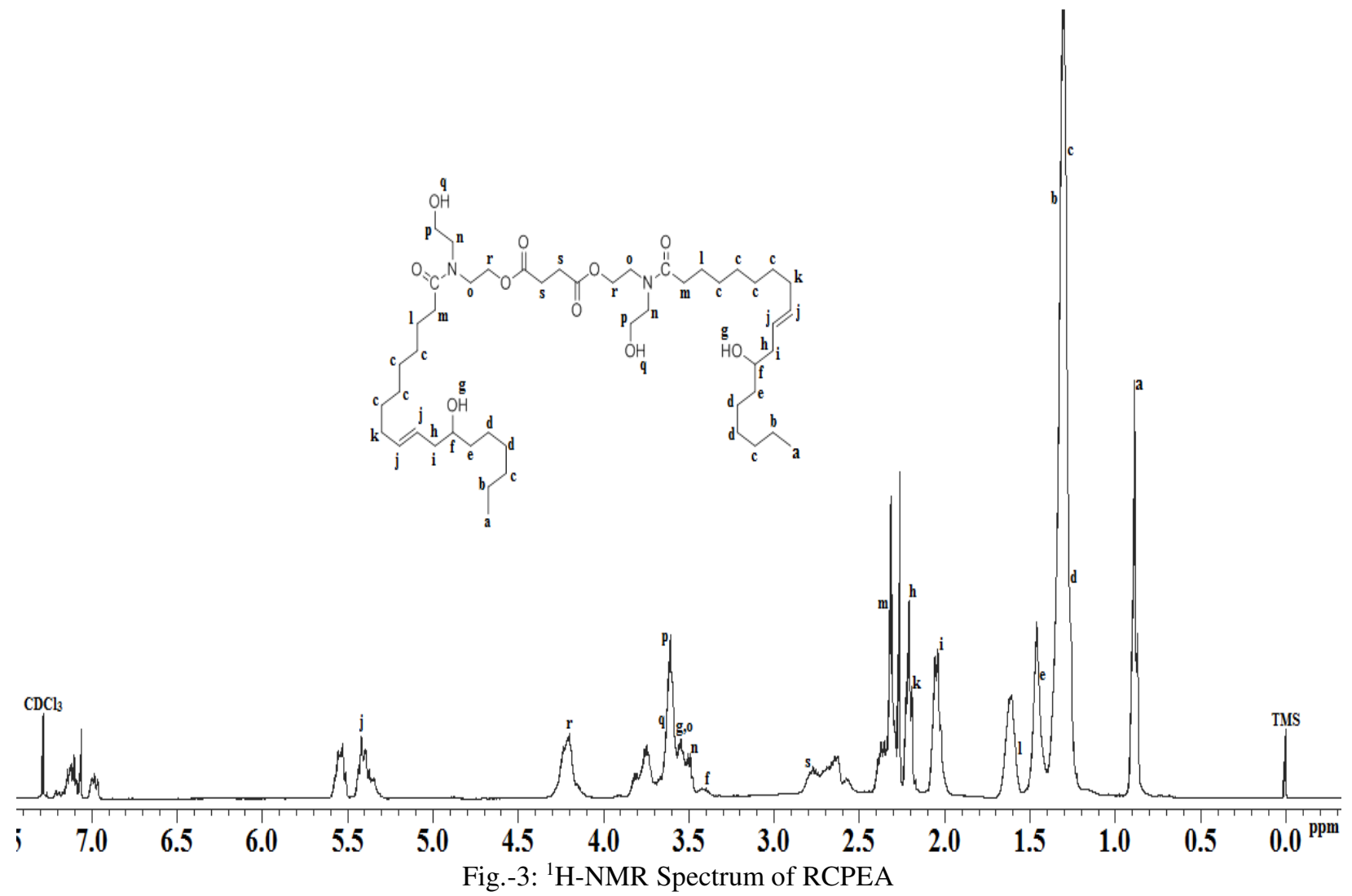

1009

POLYURETHANE COMPOSITES FROM CASTOR SEED OIL

T.O. Siyanbola et al. 
RASĀYAN J. Chem.

Vol. 10 | No. 3 |1003 - 1014 | July - September | 2017

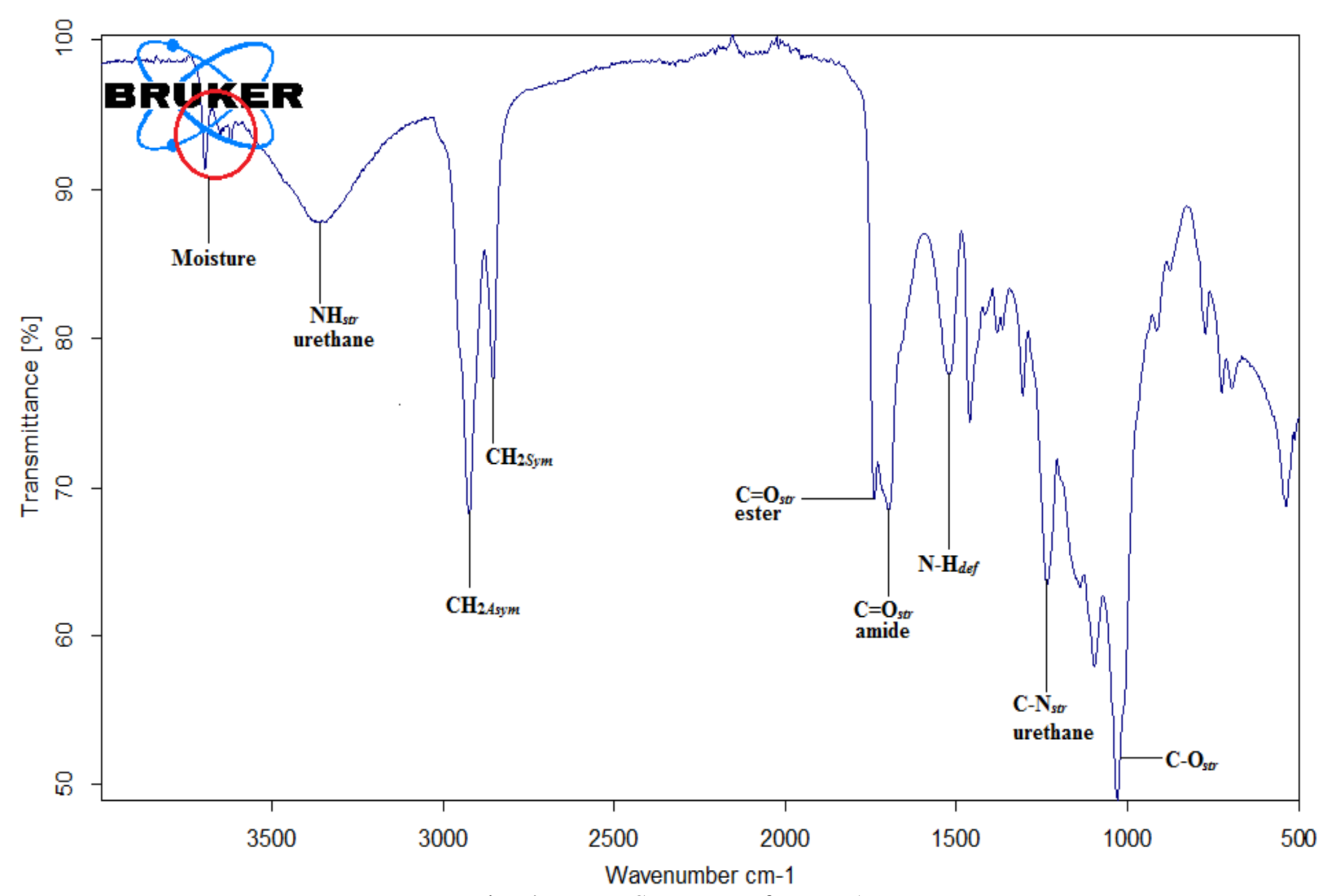

Fig.-4: FT-IR Spectrum of PURFA

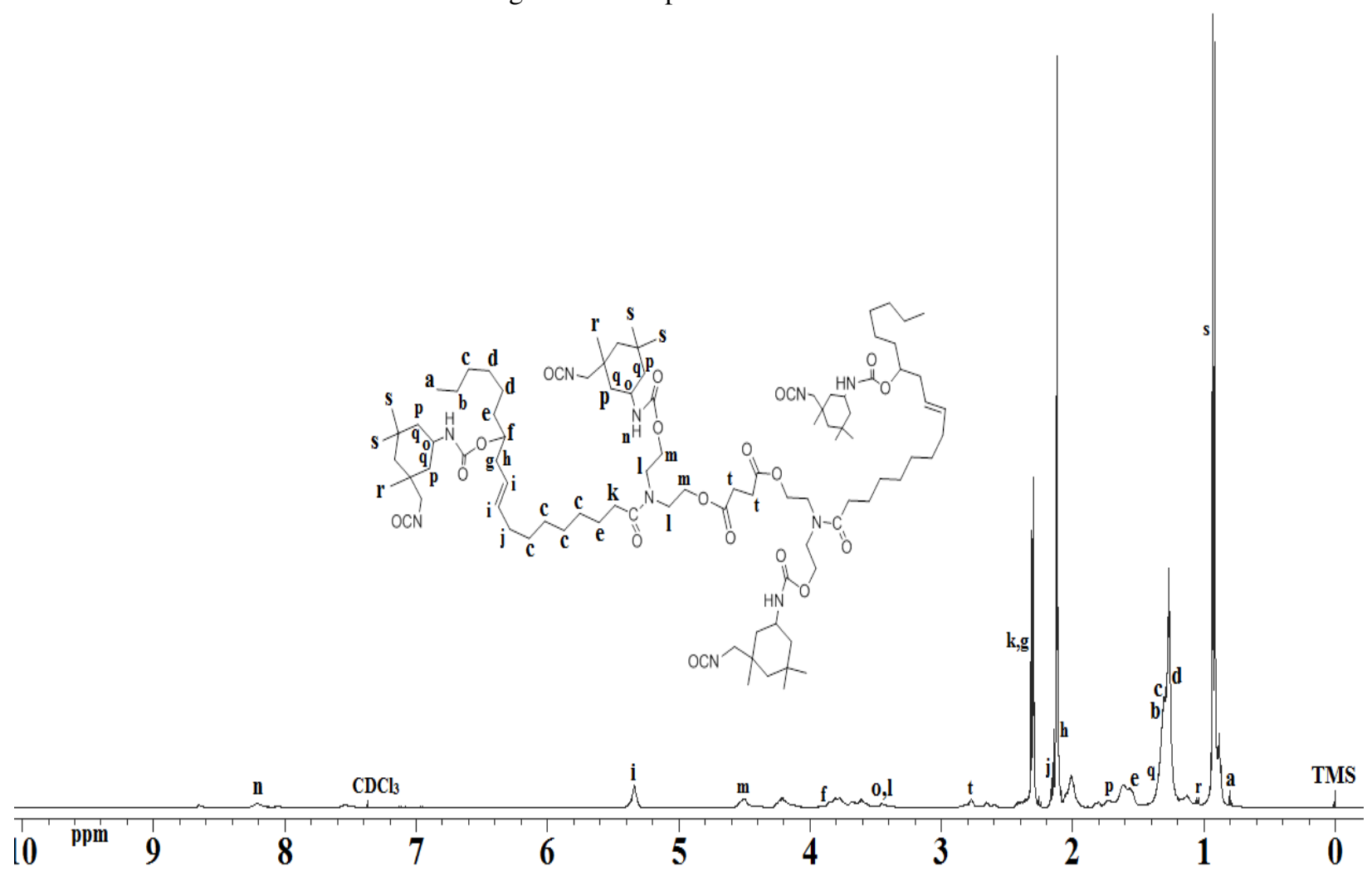

Fig.-5: ${ }^{1} \mathrm{H}-\mathrm{NMR}$ Spectrum of PURFA 
RASĀYAN $J$. Chem.

Vol. 10 | No. 3 |1003 - 1014 | July - September | 2017

The ${ }^{13} \mathrm{C}-\mathrm{NMR}$ in Figure 6 further corroborates the formation of PURFA. From the study, the chemical shift for carbonyl carbon $(-\mathbf{C}=\mathrm{O})$ bearing the urethane $\mathrm{N}-\mathrm{H}$ was observed at $\delta=155.6 \mathrm{ppm}$ and the cyclohexane carbons (x, y, a', b', c') of IPDI were also seen at 42.6, 48.0, 18.6, 22.3 and 49.3 ppm respectively. Chemical shift representing terminal methyl group carbons $\left(-\mathrm{CH}_{3}\right)$ of the fatty acid chains is represented at $\delta=14.08 \mathrm{ppm}$ whereas, those of the internal $-\mathrm{CH}_{2}$ - carbons of the fatty acid chains $(\mathrm{b}, \mathrm{c}, \mathrm{d}$, e, f, g) appear at $\delta=22.49,31.83,29.21,29.59,34.82$ and $38.72 \mathrm{ppm}$ respectively. The double bond carbons $(-\mathbf{C}=\mathbf{C}-)$ on the fatty acid chains on position $\mathrm{i}$ and $\mathrm{j}$ resonate at $\delta=122.04 \mathrm{ppm}$ and $133.62 \mathrm{ppm}$ respectively. The carbonyl carbon at position "s" resonates at $\delta=173.1 \mathrm{ppm}$.

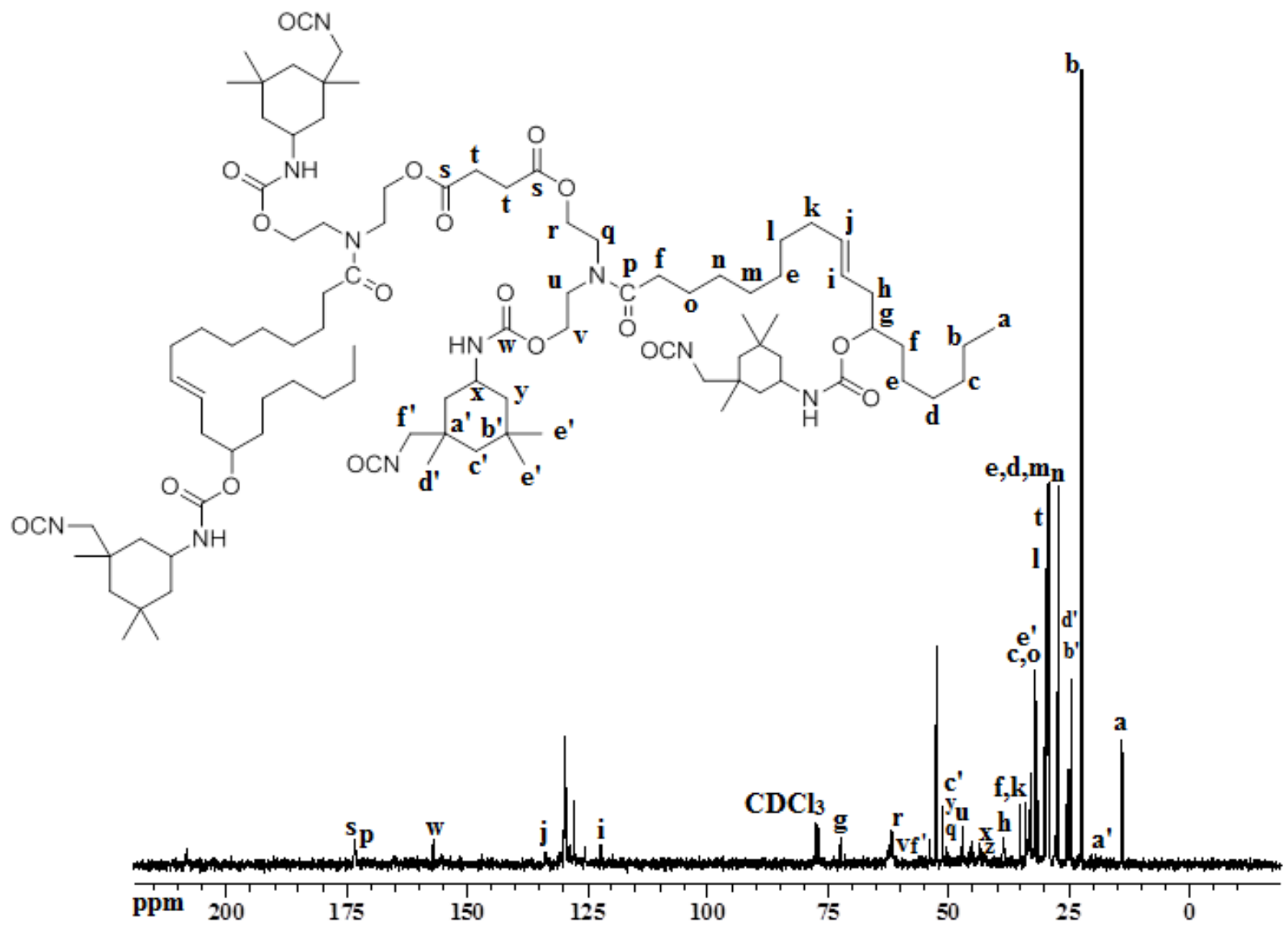

Fig.-6: ${ }^{13}$ C-NMR Spectrum of PURFA

\section{Physico-Chemical Characteristics}

Table-1 presents the physicochemical characterization of RCSO (Ricinus communis seed oil), HERCA ( $N, N^{\prime}$-bis(2-hydroxy ethyl)-12-hydroxy Ricinus communis oil fatty amide), RCPEA (Ricinus communis polyesteramide) and PURFA (polyurethane of the amide). The hydroxyl value of HERCA is approximately three more than that of RCSO, this is due to the contribution hydroxyl functional group provided by diethanolamine in amide formation. This is expected to drop geometrically in PURFA, as these hydroxyls are used up for urthanation. This observation is in agreement with Zafar et al. ${ }^{11}$ and Siyanbola et al. ${ }^{12}$ The observed decrease in saponification and iodine values from RCSO to HERCA and later RCPEA and PURFA confirms cross linking inclinations within the polymer matrix hence, increase in molar mass of the resulting polymer product. The solubility test of resins (HERCA, RCPEA, and PURFA) was performed by taking 0.1-0.2 $\mathrm{g}$ of sample in $10 \mathrm{ml}$ of solvent and stirring well for up to 15 min and heating if necessary ${ }^{1}$. Dimethylformamide (DMF), diethyl ether, methanol, ethanol, acetone, toluene, chloroform, DMSO, MIBK, and xylene were a solvent used for solubility test. HERCA and 
RASĀYAN $J$. Chem.

Vol. 10 | No. 3 |1003 - 1014 | July - September | 2017

RCPEA showed excellent solubility (greater than 95\%) in all the tested solvent, however, PURFA showed less than $80 \%$ in methanol and ethanol.

Table-1: Physico-chemical analyses of RCSO, HERCA, RCPEA, and PURFA

\begin{tabular}{l|l|l|l|l}
\hline Parameters & RCSO & HERCA & RCPEA & PURFA \\
\hline Acid value mg KOH/g & 1.94 & 3.61 & 8.49 & ND \\
\hline Iodine value g ICl/100 g & 89.41 & 58.32 & 20.51 & 16.18 \\
\hline Saponification value $\mathrm{mg} \mathrm{KOH/g}$ & 178.5 & 158.2 & 138.6 & 119.4 \\
\hline Viscosity (cSt) at $28^{\circ} \mathrm{C}$ & 312.5 & 592.6 & 763.4 & $\mathrm{ND}$ \\
\hline Hydroxyl value \% & 162 & 406 & $\mathrm{ND}$ & $\mathrm{ND}$ \\
\hline
\end{tabular}

ND: Not Determined

\section{Anti-corrosive properties of resins}

Table-2 reveals the result of anticorrosive properties along with drying time of pristine PURFA and its hybrid forms [PURFA-ZnO-APTMS (2 wt \%) and PURFA-ZnO-APTMS (5 wt \%)]. On coated mild steel, the hybrid coatings give faster drying time when compared to that of the pristine polymer resin. This is as a result of chain entanglement in within coating system (especially, as the percentage composition of the modified nanomaterial increases within the polymer matrix) hence, unreacted free isocyanate groups chemically react with moisture in the environment. ${ }^{5,12,13}$ The seven days drying time for PURFA is high when compared with five days observed with Siyanbola et al. ${ }^{5}$ This may be due to the nature of diisocyanate (4,4'-diisocyanatodicyclohexylmethane) used in ${ }^{5}$. However, this resin stayed a longer time in the water and its films were not affected.

\section{Antibacterial activities of the films}

The antibacterial activities of PURFA, PURFA-ZnO-APTMS (2 wt $\%)$ and PURFA-ZnO-APTMS (5 wt\%) were tested on common pathogenic organisms such as Staphylococcus aureus, Escherichia Coli, Pseudomonas aeruginosa and Bacillus subtilis. ${ }^{5,14,15}$ The results of the test are presented in Fig.-7.

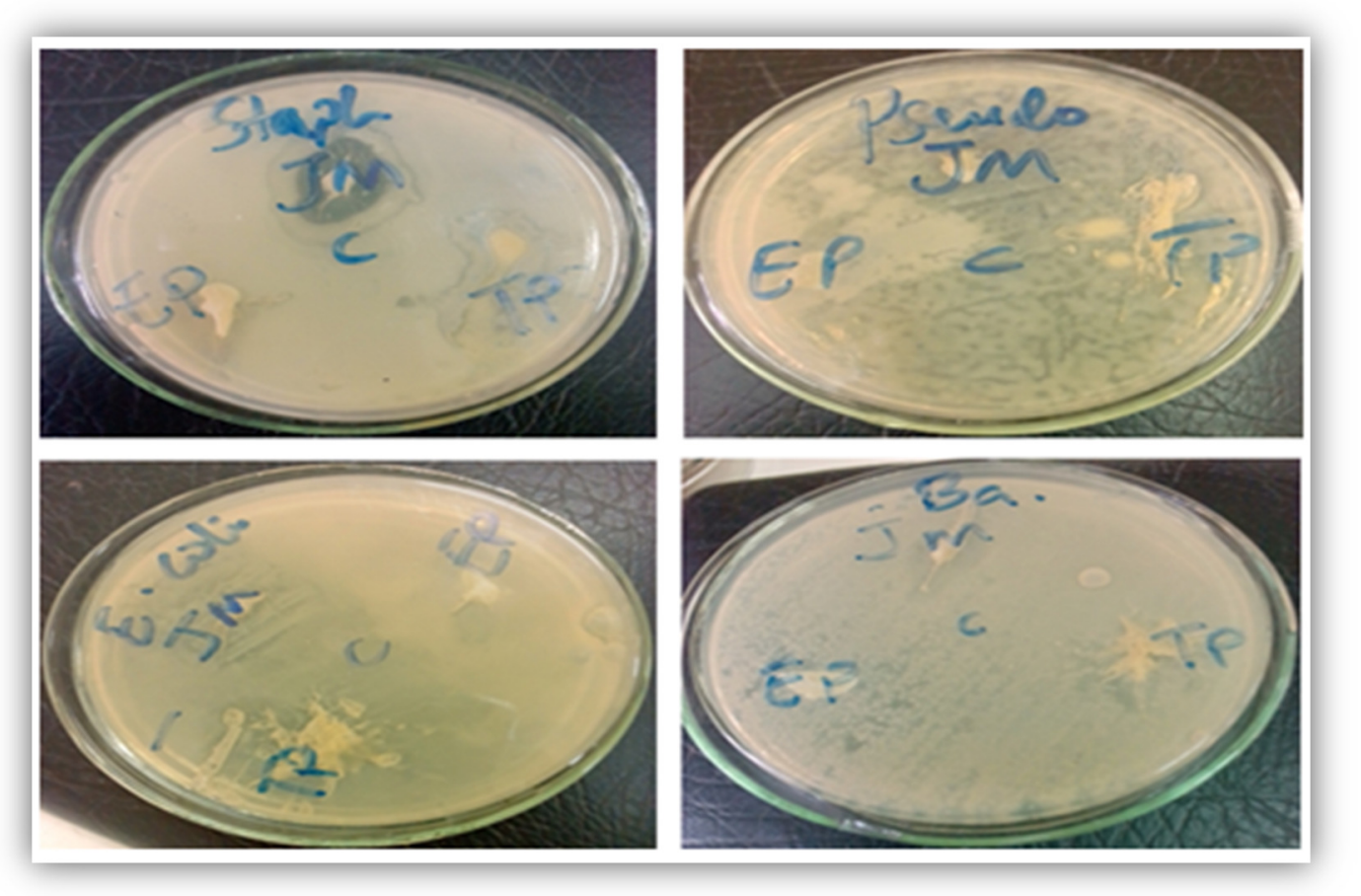

Fig.-7: Antibacterial activities of PURFA and its hybrid films

Staph $=S$. aureus, Pseudo $=P$. aeruginosa, $\mathrm{Ba}=B$. subtilis

$\mathrm{EP}=\mathrm{PURFA}, \mathrm{TP}=\mathrm{PURFA-ZnO}-\mathrm{APTMS}(2 \mathrm{wt} \%), \mathrm{JM}=\mathrm{PURFA-ZnO-APTMS}(5 \mathrm{wt} \%)$ 
The films under investigation show least inhibitive zones on B. subtilis. PURFA-ZnO-APTMS (5 wt\%) show the greatest activities on $S$. aureus plate followed by PURFA-ZnO-APTMS (2 wt $\%$ ) and PURFA having the least; this goes to confirm the antibacterial effect (with respect to concentration) of the incorporated nanomaterial in the composites coating films. Antibacterial activity was most on $P$. aeruginosa plate with PURFA-ZnO-APTMS (2 wt\%) and PURFA-ZnO-APTMS (5 wt\%) impeding the growth of the organism almost on the whole area.

Table-2: Chemical resistant and drying time of resins

\begin{tabular}{c|c|c|c}
\hline Resin code & PURFA & PURFA-ZnO-APTMS $(2 \mathrm{wt} \%)$ & PURFA-ZnO-APTMS (5 wt $\%)$ \\
\hline Drying time $^{\mathrm{a}}($ day $)$ & 7 & 4 & 2 \\
\hline $\mathrm{H}_{2} \mathrm{O}(15$ days $)$ & $\mathrm{A}$ & $\mathrm{A}$ & $\mathrm{A}$ \\
\hline $\mathrm{NaOH}(5 \%, 2 \mathrm{~h})$ & $\mathrm{C}$ & $\mathrm{B}$ & $\mathrm{B}$ \\
\hline $\mathrm{HCl}(5 \%, 10$ days $)$ & $\mathrm{C}$ & $\mathrm{A}$ & $\mathrm{A}$ \\
\hline
\end{tabular}

${ }^{\mathrm{a}}$ : Ambient cured, A : unaffected, B : slightly loss of gloss, C : film partially removed

\section{Salt spray test}

The salt spray test was used to evaluate the corrosion resistance of the coating films (Figure 8). After about 185 hours of salt spray, panel A and B remains almost unaffected except for the surface dullness of the mild steel coating. Panel $\mathrm{C}$ is the representation of the reverse of the unprotected mild steel.

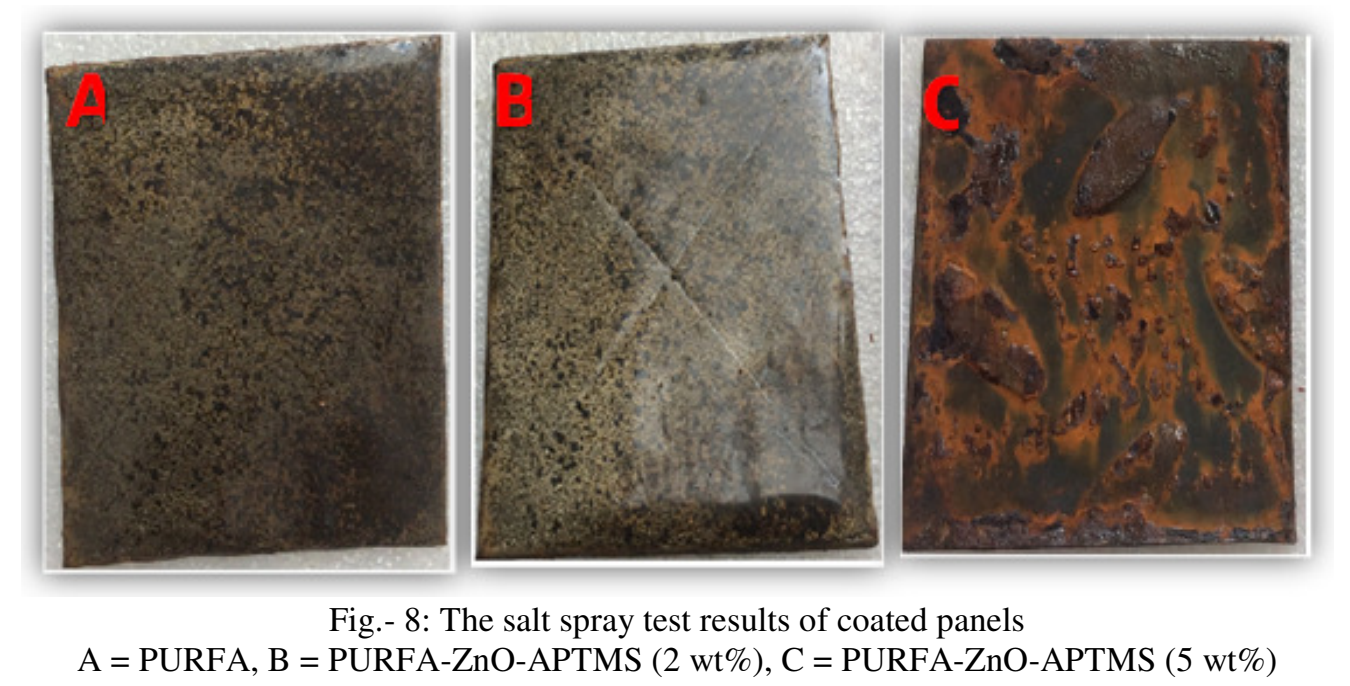

\section{SEM analysis}

The SEM micrographs of PURFA-ZnO-APTMS (2 wt $\%$ ) and PURFA-ZnO-APTMS (5 wt $\%$ ) is presented in Fig.-9. The SEM micrographs show indication of the uniform distribution of ZnO-APTMS hybrid nanoparticles within the matrix of PURFA. However, the roughness is greater with that of PURFA-ZnOAPTMS (5 wt $\%)$.

\section{CONCLUSION}

The synthesized APTMS-ZnO was successfully incorporated within PURFA matrix. The siloxane crosslinking effect reduces the drying time of the RCSO ambient cured urethane composites. The nanoparticles are seen to influence the antibacterial activities of the coating films. The viscosity of the synthesized polyester (RCPEA) and its improved hydroxyl functionality facilitates easy modifications towards different product formulations.

\section{ACKNOWLEDGEMENT}

Dr. Tolutope Oluwasegun Siyanbola appreciates the contributions of Indian Institute of Chemical Technology, Hyderabad India and Covenant University, Ota, Nigeria for providing a research base for this work. 
RASĀYAN $J$. Chem.

Vol. 10 | No. 3 |1003 - 1014 | July - September | 2017
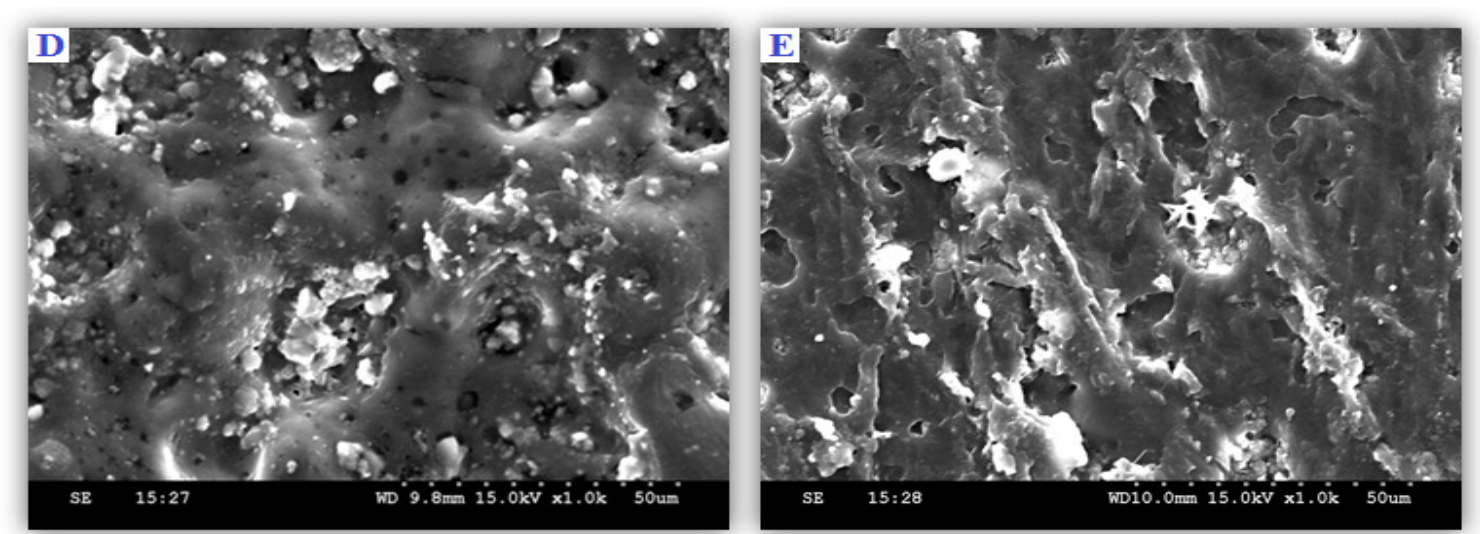

Fig.-9: SEM micrograph of PURFA-hybrid films

$\mathrm{D}=$ PURFA-ZnO-APTMS (2 wt $\%), \mathrm{E}=$ PURFA-ZnO-APTMS (5 wt $\%)$

\section{REFERENCES}

1. T.O. Siyanbola, K. Sasidhar, B.V.S.K. Rao, R. Narayan, O. Olaofe, E.T. Akintayo and K.V.S.N. Raju, J. Am. Oil Chem. Soc., 92, 267 (2015)

2. Y. Lu and R.C. Larock, ChemSusChem., 2, 136 (2009)

3. G. Imran, S. Ahamad, I. Altaf and S.A. Ahmad, Chem. Sci. Trans., 4, 1007 (2015)

4. S.Z. Erhan, Industrial Uses of Vegetable Oils, AOCS Press, Champaign, IL, 2005.

5. T.O. Siyanbola, K. Sasidhar, B. Anjaneyulu, K.P. Kumar, B.V.S.K. Rao, R. Narayan, O. Olaofe, E.T. Akintayo and K.V.S.N. Raju, J. Mater. Sci., 48, 8215 (2013)

6. K.K. Jena, R. Narayan and K.V.S.N. Raju, Polym. Int., 61, 1309 (2012)

7. M.E. Linday Practical introduction to microbiology. E and F.N. Spon, London, p. 177, (1962)

8. A. Adewuyi, R.A. Oderinde, B.V.S.K. Rao and R.B.N. Prasad, J. Surfact Deterg., 15, 89 (2011)

9. T.A. Misiev Powder Coatings Chemistry and Technology, Wiley, New York (1991)

10. K.K. Jena, T.K. Rout, R. Narayan and K.V.S.N. Raju, Polym. Int., 61, 1101 (2012)

11. F. Zafar, S.M. Ashraf and S. Ahmad, Prog. Org. Coat., 51, 250 (2004)

12. T.O. Siyanbola, K. Sasidhar, R. Narayan, B. Anjaneyulu, B.V.S.K. Rao, O. Olaofe, E.T. Akintayo and K.V.S.N. Raju, Int. Res. J. Pure Appl., 8, 58 (2015)

13. D.K. Chattopadhyay and K.V.S.N. Raju, Prog. Polymer. Sci., 32, 352 (2007)

14. E. Kenawy, F.I. Abdel Hay, A. El-Raheem, R. El-Shanshoury and M.H. El-Newehy, J. Polym. Sci., 40, 2384 (2002)

15. J. Hazziza-Laskar, G. Helary and G. Sauvet, J. Appl. Polym. Sci., 58, 77 (1995)

[RJC-1811/2017] 